differentiation by stimulating DNA synthesis. ${ }^{2}$ Furthermore, both insulin and IGF-1 down regulate sex hormone binding globulin (SHBG) resulting in an increase in serum oestrogens and androgens. Sex hormones are mitogens that may contribute to GI proliferation. Adipose tissue also up regulates inflammatory mediators including cytokines, such as TNF-alpha and interleukin-6 (IL-6). Adipose tissue, particularly visceral tissue, is a source of cytokines with serum leptin and IL-6 correlating well with increasing body mass index. While many GI cancers are associated with pre-malignant inflammatory states it is not yet understood how adipose-derived cytokines may influence this process. Of relevance is that TNF-alpha and IL-6 are potent mitogens. Finally, local physical factors may be important; oesophageal reflux increases with increased abdominal adiposity. The refluxate can promote Barrett's metaplasia and consequently adenocarcinoma.

\section{Epidemiological evidence}

The experimental work is supported by data from multiple epidemiological studies reporting positive associations between obesity and cancers of the oesophagus, pancreas and large bowel. For colorectal cancer, the most common cancer of the digestive tract, a meta-analysis of 31 epidemiological studies assessed the effects of obesity in 70,000 incident cases. ${ }^{3}$ The estimated relative risk of colorectal cancer was $1.19(95 \%$ confidence interval $(\mathrm{CI})=1.11$ to 1.29 ) in obese people (BMI $>30 \mathrm{~kg} / \mathrm{m}^{2}$ ) compared to those with a normal weight $\left(\mathrm{BMI}<25 \mathrm{~kg} / \mathrm{m}^{2}\right)$. A dose-response existed with every $2 \mathrm{~kg} / \mathrm{m}^{2}$ increase in BMI (approximately $5 \mathrm{~kg}$ of extra weight) increasing the risk by $7 \%$ ( $95 \% \mathrm{CI}=4$ to $10)$. If the association is causal, then a $2 \mathrm{~kg} / \mathrm{m}^{2}$ reduction in BMI in the population would prevent approximately 2,600 colorectal cancers annually in the UK. ${ }^{4}$ In pancreatic cancer, a tumour with an extremely poor prognosis, the effect of obesity was studied in a meta-analysis of 6,391 cases. ${ }^{5}$ The summary relative risk per unit increase in BMI was $1.02(95 \% \mathrm{CI}=1.01$ to 1.03 ), as in a $2 \%$ increase risk for each unit of BMI. This translates for those with a BMI of over $30 \mathrm{~kg} / \mathrm{m}^{2}$ into a relative risk of 1.19 ( $95 \%$ CI $=1.10$ to 1.29 ) compared to those with a BMI of $22 \mathrm{~kg} / \mathrm{m}^{2}$. A reduction of two units in the population's BMI would reduce the annual number of cases of pancreatic cancer in the UK by 300 . For oesophageal adenocarcinoma, whose incidence has risen faster than any other cancer of the digestive tract, a meta-analysis of six case-control studies reported a 54\% (95\% $\mathrm{CI}=39 \%$ to $71 \%$ ) increased risk with each $5 \mathrm{~kg} / \mathrm{m}^{2}$ rise in BMI. ${ }^{6}$ Based on these figures, a relatively large reduction in BMI of one standard category $\left(5 \mathrm{~kg} / \mathrm{m}^{2}\right)$ could prevent approximately 3,100 cases of oesophageal adenocarcinoma in the UK.

\section{Conclusions}

While the link between obesity and cardiovascular disease is well established there is now emerging evidence supporting a causal association with cancers of the GI tract. A more detailed understanding of the biological mechanisms is still needed to confirm the link, but the potential rise in these cancers should prompt action to encourage a reduction in the BMI of the population. A decrease in the BMI by two units may prevent approximately 4,000 cases of digestive cancers annually in the UK. This strategy would be of relevance to general practitioners and public health physicians to help prevent cancer, to medical and surgical gastroenterologists and oncologists to reduce the number of patients referred with cancer, and to managers who would need to deal with the increased resources required. Perhaps in this century, obesity will be identified as the main risk factor for cancers of the digestive tract, just as in the last, smoking was for lung cancer.

ANDREW R HART Senior lecturer in gastroenterology School of Medicine, Health Policy and Practice, University of East Anglia, Norwich

MICHAEL PN LEWIS

Consultant gastrointestinal surgeon

Department of Upper Gastrointestinal Surgery, Norfolk and Norwich University Hospital NHS Trust

\section{References}

1 Kaaks R, Lukanova A. Energy balance and cancer: the role of insulin and insulin-like growth factor-1. Proc Nutr Soc 2001;60:91-106.

2 Jones J, Clemmons D. Insulin-like growth factors and their binding proteins:biological actions. Endocr Rev 1995;16:3-34.

3 Moghaddam A, Woodward M, Huxley R. Obesity and risk of colorectal cancer:a meta-analysis of 31 studies with 70,000 events. Cancer Epidemiol Biomarkers Prev 2007;16:2533-47.

4 Office of National Statistics. Cancer registration statistics in England. London: ONS, 2007.

5 Berrington de Gonzalez A, Sweetland S, Spencer E. A meta-analysis of obesity and the risk of pancreatic cancer. Br J Cancer 2003;89:519-23.

6 Smith M, Zhou M, Whitlock G et al. Esophageal cancer and body mass index: results from a prospective cohort study of 220,000 men in China and a meta-analysis of published studies. Int $J$ Cancer 2008;122:1604-10.

\section{What is happening to English neurology: an update}

In 2008, Clinical Medicine kindly published my analysis of the availability of neurology outpatients by primary care trust (PCT) of residence from 2003 to $2006 .^{1}$ The information was also given to the Department of Health (DH). I have extended this study to April 2009 and the trends are essentially the same. The number of appointments in neurology has continued to rise (by $11 \%$ per year, compared with $3 \%$ per year for general medicine) with no apparent ceiling. The follow-up to new appointment ratio has dropped from 1.6 to 1.46 over the same time. The lottery in regional access has not changed (Fig 1).

I recently approached the $\mathrm{DH}$ to ask for the agreed outpatient tariffs between PCTs and providers in secondary care. Neurology is unusual in that there has been no nationally agreed tariff; instead, local tariffs have been negotiated between hospitals and PCTs. The DH held no record of the agreed tariffs. Using freedom of information legislation I then contacted all 152 PCTs to ask to which providers their patients were referred and at what cost. In total, 104 PCTs responded, giving the tariffs for 121 providers in England; other PCTs used the exemption that the information was commercially sensitive. The information that has been made available 


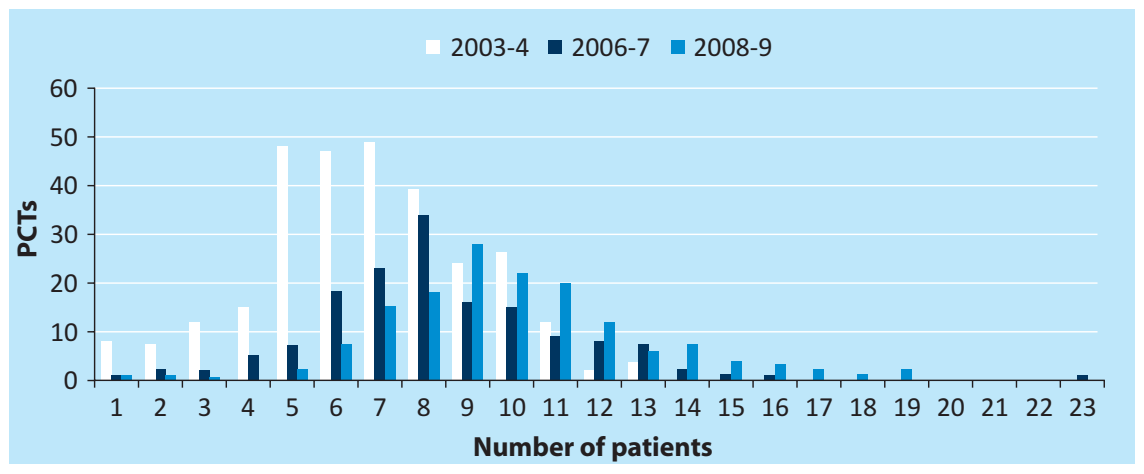

Fig 1. The number of primary care trusts (PCTs) referring a given number of patients (new appointments in neurology per 1,000 population) in 2003-4, 2006-7 and 2008-9. Note that the number of PCTs in England changed from 302 to 152 in 2006.

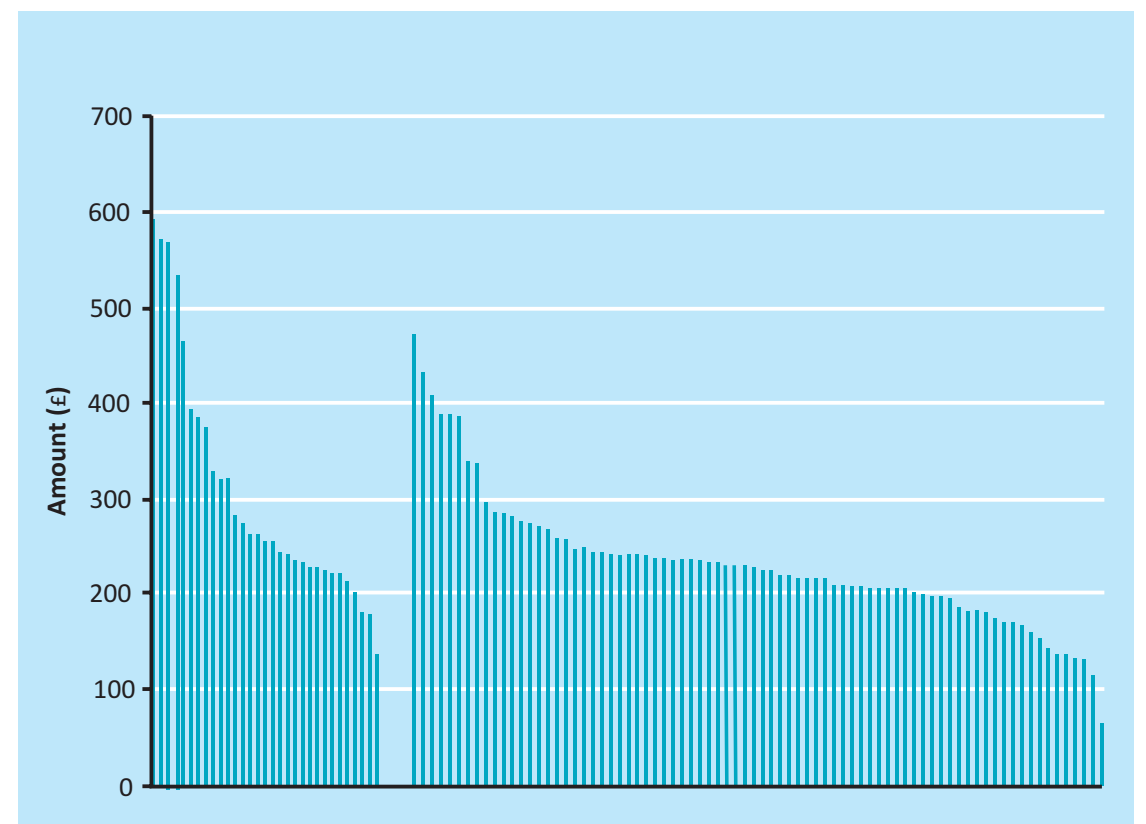

Fig 2. New outpatient tariff for 121 neurology providers in England (four providers have separate tariffs for secondary and tertiary care).

provides a chaotic picture of service provision and cost per appointment. The cost, to a PCT, of a new consultant outpatient appointment in neurology in England varies from $\mathfrak{E} 67$ to $\mathfrak{E} 592$ and the cost of a follow-up appointment from $\mathfrak{E} 64$ to $\mathfrak{£} 416$. The average for a new consultant appointment in 2009-10 was $£ 249$ (standard deviation (SD) $£ 90$ ), the average follow-up was

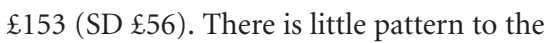
tariffs. The tariffs do not appear to recognise whether a provider has secondary or tertiary facilities (Fig 2), neurology beds or neurology on-call. There is no relationship between the price a PCT pays for its neuhealthcare in England appears to have had diverse effects on neurology. The expansion in outpatient numbers is a response to demand but demand has not been limited by an expensive neurology service or transferred to a cheap neurology service. There are watersheds, with three patients seen on one side of a line for the price of one on the other. General practitioners (GPs) may not know the cost of referral. If they do know the cost perhaps they value their local service and see the extra cost as justifiable. Some providers appear to have a monopoly, with PCTs accepting the high cost of their local service rather than, for example, arranging transport to a more distant provider. A limited supply and distribution of neurologists may have facilitated this. The negotiating process may have been muddled by commercial secrecy or a failure to ask questions. For a neurology service seeing 4,000 patients per year a change in new patient tariff from

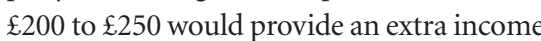
of $£ 200,000$ per year, enough to provide two more neurology consultants to do the work that is already being done.

This information does not necessarily condemn the introduction of a free market in healthcare but it does pose awkward questions for the DH. How much should a neurology appointment cost a commissioning group, PCT or GP, and why should it be more expensive in some parts of the country than others? Why, given the problem in neurology service provision, ${ }^{1,2}$ does the DH not know the agreed tariffs across the country? How many neurologists do you need to run a national neurology service?

Unlimited demand and limited supply has meant that, so far, both expensive and cheap neurology services have flourished and there is no evidence that the free market is correcting the national lottery of neurology care. My rationale for publicising this information is to draw attention to neurology's continuing service idiosyncracy and to allow providers and purchasers more informed negotiation. Many of the PCTs requested that I did not publish the information provided and hence no individual PCT or provider name is given.

PAUL MORRISH

Consultant neurologist

Gloucestershire Hospital NHS Foundation Trust

\section{References}

1 Morrish P. What is happening to English neurology. Clin Med 2008;8:576-8.

2 All Party Parliamentary Group for Parkinson's Disease. Please mind the gap: Parkinson's disease services today. London: Houses of Parliament London, 2010. 